\title{
Community Learning Needs in Gender Based Violence with Special Reference to Northern Districts in Sri Lanka
}

\author{
Saja A \\ Queensland University of Technology, Australia
}

\begin{abstract}
The communities in the Northern Sri Lanka recognize gender based discrimination as one of the major problems in their daily activities that leads to disturbances of life at family and community level. There was hardly any evidence of community based mechanisms to address the roots causes of gender based discrimination. Although communities have a basic understanding of the causes of gender discrimination and Gender Based Violence (GBV), key community based entities such as Women Rural Development Societies (WRDS) and youth groups lacked clear understanding of gender based issues, legal framework and the available state mechanisms. Communities' interaction with the GBV stakeholders also seemed to be very weak and lacked confidence in GBV response mechanisms. Despite ad-hoc interventions to address GBV-primarily reactive, GBV remains a great concern for communities. The existing development programmes failed to focus on prevention of $G B V$, long term commitment and structured mechanisms from community to district level. Communities were little aware of the available mechanisms to address GBV too. Learning needs assessment carried out in 2013 in two selected districts in the Northern Province, highlighted that regular awareness raising to sensitize the communities on GBV, confidence building programs specifically for the youth and vulnerable women groups such as women headed households were found to be immediate priorities. Community watch groups could be formed from WRDS and trained to identify, monitor and respond to GBV and should be linked to mechanisms in divisional and district levels. The network can be widened and strengthened through connecting networks in neighboring villages to make them part of larger women voice networks at district and national level. Making men understand gender equality and rights of women are also key to the successful programme outcomes of any future interventions.
\end{abstract}

KEYWORDS: Awareness, GBV, gender, learning needs, Sri Lanka

Corresponding author: A. Saja, Email: saja.aslam@gmail.com 


\section{INTRODUCTION}

Gender Based Violence (GBV);

"refers to any harm perpetrated against a person's will on the basis of gender-the socially ascribed differences between males and females. It is based on an unequal power between men, women, boys and girls. Women and girls are often the targets because of social norms and beliefs that perpetuate their second-class social status. GBV includes physical, sexual and psychological abuse of women and girls in the home, community and in schools; trafficking and widespread sexual violence and exploitation during and after conflicts and natural disasters" (CARE 2012 p.1).

GBV is identified to be one of the significant social and public health problems in Sri Lanka (Jennifer et al., 2011). GBV is often discounted relative to other crimes despite the fact that laws, policies, institutions and practices remain insensitive to gender concerns. On the other hand, women and young girls - the main victims of this kind of violence- and their families usually remain silent and avoid seeking remedies.

Jennifer et al. (2011) further highlighted that the majority of the victims of the GBV cases are women, although it includes violence against men and women. Unequal gender relations and discrimination are the root causes of GBV. The pattern of GBV in Sri Lanka encompasses physical, sexual, psychological and emotional violence and parallels current worldwide trends (Jennifer et al., 2011). A good understanding of GBV prevalence and trend in Sri Lanka is lacking due to the absence of systematic data (Jayasundere, 2009). Further, ICG (2011) reported that:

"Explicit allegations of domestic violence and sexual abuse do not make the headlines frequently. There is still significant stigma associated with being a victim of sexual abuse or seeking separation from a husband, and impunity for violence against women remains the rule in the North - as is true across Sri Lanka. As a result, many incidents are not reported at all, while others are exaggerated"

This leaves an incomplete picture of the experiences of women particularly in the context of North. "It is evident that GBV is currently not addressed adequately by the health care and other relevant sectors in Sri Lanka" (Jennifer et al., 2011). IDP camp setting, where most of the returnees lived after displacement, had led to the breakdown of community safety mechanisms which further increased the risks of GBV violence. In the context of the North, after the return process, there has been continuous reporting on the GBV issues and lack of mechanisms to address the issues at the community and government level. Acquiring GBV awareness is an appropriate step in advancing their community involvement. In addition, engaging young men to address women's issues is a proven way to address GBV. Youth are a strong catalyst too to promote social changes. As the state mechanism strengthened to provide services, the services are needed to be extended by them and communities need to be equipped with understanding to demand for those services. It is also important to develop a common voice for women at the grass root level.

In order to have a grounded understanding of GBV and gender issues at community level, it is important to understand the current level of knowledge and understanding existing mechanisms to address the GBV at community level. The objective of the study is to understand the community perceptions and current level of knowledge, any existing mechanisms in order to map the needs and gaps to address GBV issues at community level by consulting youth and women in the Northern Sri Lanka.

\section{BACKGROUND}

ICG (2011) report on women insecurity in the North and East Sri Lanka underlined that there are increasing violence within families and villages is one of the greatest current concerns in 
the North. The ICG (2011) report further highlighted that:

"There are stories of rape and physical abuse within families. There are also reports of men abandoning their wives for other women and intimidating them to not to challenge the second marriage. This physical and sexual aggression, combined with growing alcohol use and other pressures, has been debilitating for many families. There are widespread reports of an increase in under-age pregnancies".

Girls and women experienced enormous challenges as a result of accumulated impact of violence, particularly the impact on their physical and mental health and its consequences, both immediate and long term (Jennifer et al., 2011). Regular awareness programmes are needed for the communities to address GBV. One of the recommendations for the international organizations to address GBV suggested by ICAN (2013) is to "strengthen local CSO capacities for legal advocacy, public awareness raising, networking and service delivery, through funding, technical assistance and ensuring systematic and structured engagement with state and international counterparts". All what is required is an extensive strategic and long term programming to address gender based violence in all realms from policy to local level programming at the community level (Jayasundera, 2009).

According to the Child Development and Women Empowerment Ministry data released in September 2010, there are around 40,000 war widows in the North. One particularly vulnerable group to GBV is young widows who were forced into marriages to avoid being recruited during the period of war. Nevertheless, it is evident that structures like Women Rural Development Society (WRDS) and youth groups are becoming stronger to collectively seek assistance. WRDS raise a strong voice in demanding the state institutions to take immediate actions to fulfill community needs. New initiatives needs to support strengthening the existing groups with the long term vision to enable these groups to work in close collaboration with the government service providers and obtain services available for GBV prevention, curative and rehabilitative efforts. Family structure has been greatly affected due to the past war and the weakened family structure has a flow on effect to the broader community, where the prevalence of issues such as alcoholism, domestic violence, gender based violence, child abuse and other mental health and psychosocial issues are considerably high. Bad coping mechanisms such as alcohol abuse or aggressive behavior are prevalent and result in many cases of domestic violence and child abuse.

A project implemented in the northern districts of Sri Lanka by CARE International aimed to "raise awareness at the community levels on GBV to develop community based response mechanisms." Many other awareness raising activities has been implemented by many organizations on Gender Based Violence and Child Rights in the North, such as the projects launched by Legal Aid Commission. However, there have been several needs and gaps exist. linkages with psychosocial and mental health programmes to address GBV under several projects need to be carefully mapped out in order to design new programmes which could complement the ongoing initiatives within the same framework of action to prevent and respond to GBV. The reach of GBV awareness to the communities needs to be further improved and community based mechanisms should be given priority to prevent and respond to GBV issues. New potential stakeholders such as religious leaders and leading role models should be explored. Lessons learnt and good practices from other locations should also be harnessed through networks of activists.

\section{METHODOLOGY}

The study was conducted in four divisional secretariat (DS) divisions in two districts in 
Northern Province of Sri Lanka (Figure 1). Selected DS divisions were:

- Puthukudiyiruppu and Maritiempatu DS divisions in Mullaitivu District, and

- Poonagay and Karaichchi DS divisions in Killinochchi District.

Since this study aims to explore the learning needs, a qualitative study was employed. Semi Structured Interview (SSI) questions and participatory tools were used to conduct the Focus Group Discussions. Limitation to this study was that the study was conducted in only two districts among the five districts in the Northern Province of Sri Lanka. However, some data available from secondary sources focusing the entire Northern Province helped to complement the primary data collected during the focus group discussions in this study. Details of Focus Group Discussions (FGD) are as follows:

- Focus Group Discussions (FGD) with Women Rural Development Society (WRDS) members (29 females), comprising of a mix age group from 8 Grama Niladhari (GN) divisions in 2 DS divisions, and

- Two Focus Group Discussions with two groups of youth comprised of 32 youth from both sexes (16 boys and 16 girls), who were undergoing vocational training from $9 \mathrm{GN}$ divisions in 2 DS divisions.

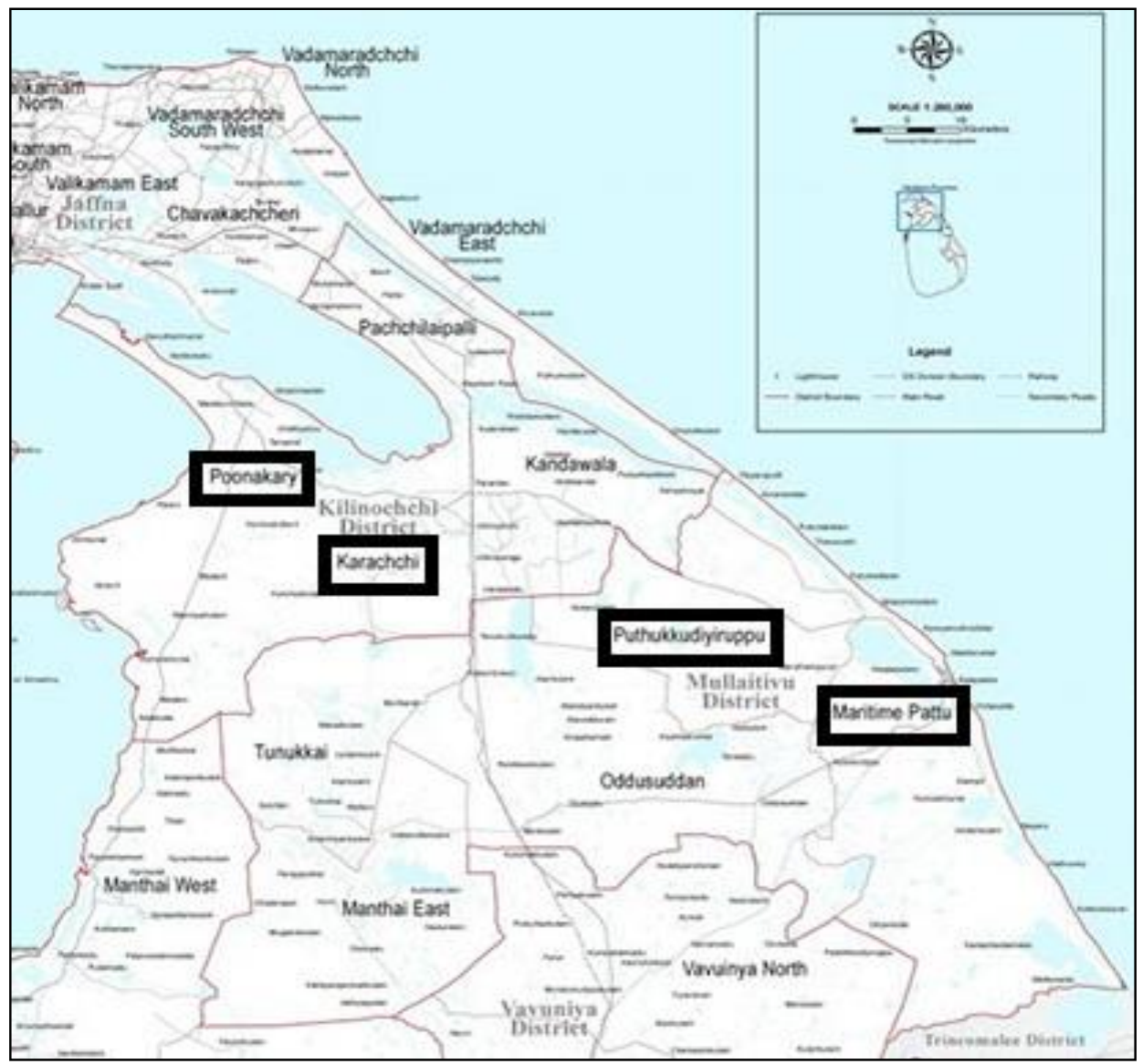

Figure 1: Location of the four DS divisions in the Northern districts in Sri Lanka (Locations are highlighted in the black box)

Source: CIRM 


\section{RESULTS AND DISCUSSION}

Findings of the assessment in all four locations are summarized below in four key areas in line with the methodology adopted for this assessment.

1. Knowledge level of concept of Gender, Difference between Gender and Sex as well as the Gender equality.

2. Key GBV issues at the community level.

3. Currently available mechanisms to address the key GBV issues at the community level

4. Future requirements of the communities to address the GBV issues

\subsection{Knowledge level about GBV}

Conceptual knowledge of gender and difference between gender and sex were very low among the people in the study area. They could not differentiate sex and gender and sometimes explained gender is same as sex.

However people were able to explain the gender equality as to what it should be and were able to identify the key causes for the gender inequality in their villages. In summary;

- Level of respect given by the society

- Culture of the society

- Social differences

- Perception by the society

- Social ignorance of women by the society

- Lack of awareness of women roles and rights

People were able to list some key GBV issues. They include;

- Harassments at the household/family level (by husbands)

- Perception by the society (as women lacks leadership qualities)

- Child abuse

- Growing and caring children with gender differences
- Negative social perception of single women (divorced or widow)

- Harassment of women due to alcoholism

- Usage of mobile phones to watch pornography leading to sexual exploitation among the youth

\subsection{Key GBV issues at the community level}

Some of the key issues among the general issues highlighted by the people were related to GBV, while the other issues could lead to GBV issues. Major common issues in all villages were unemployment for the youth and lack of opportunities for women. There is a general notion in the community is that the main role of the women is home maker and looking after their kids for their well-being. Although most of the issues were related to economical/livelihood, there has been consistent issues related to education and leadership in addition to the overarching cultural and social limitations as to what a women can or should do in these communities.

- No electricity in villages distant from the main roads

- Lack of transport facilities available

- Families finding it difficult to pay back loans adding them more pressure on their livelihood

- Schools are not functioning properly and lack of teachers

- Consumption of illegal alcohol leads to domestic violence

- Marginalization of villages/communities giving low status compared to other neighboring villages

The above general issues further increase the risk for women in the Northern context as there is large number of women were either widowed, unmarried, divorced or living separately from their husbands and most of them were heading households and the majority have limited access to livelihood opportunities. 
Some specific issues on GBV highlighted by the participants of this assessment were;

- Women Headed Households carry the family responsibility and struggling to find livelihood leads to SGBV issues.

- Large variation in the wages for women for the same work men do.

- Cultural practices do not allow the women to participate in the work that men do. If they participate, there has been discrimination in the wage for the same type of work.

- Suspicion of woman (particularly widow or divorced woman) talking to or working with men.

- Verbal, physiological and physical abuses for women in work places.

Both WRDS and Youth groups had limited understanding of GBV prevention and response mechanisms. There have been little differences in priority GBV issues between different study locations depending on the location and social factors. For example in one area, the major issue was the production and consumption of illegal alcohol and the inward migration of men workers from far places, whereas in another location key issues include outward migration of men for jobs to far places leaving the women living alone for long time period. Therefore detail root-cause analysis of problems in each community context will be helpful to further analyse the GBV issues to devise appropriate community based mechanisms.

\subsection{Available mechanisms to address GBV issues at the community/district level}

No specific group to work for GBV issues was identified in the locations of this study. However WRDS in the village level and the youth group/club are interested do something against the GBV issues in their villages. Further, there was lack of consistency in understanding and less awareness among the women as well as the youth about the Gender based rights, issues or violence's and the referral mechanisms to address GBV issues.

- There were hardly any structured mechanism at the community level in the locations of this study to address the GBV issues. However people noted that there are women action networks in the neighboring villages. Therefore it is important for these communities to get them organized and trained, so that they can make linkages with women networks in neighboring villages to strengthen their position at the divisional level and then in the district.

- Gender desk in the Divisional Secretariat (DS) office: Only very few women were aware of the Women Development Officer (WDO) or the help desk for women issues at the DS office. Often, people approach Grama Niladari (GN) to resolve family or community issues and there is less awareness among the women as well as men about the women rights, issues or violence's and the referral systems.

- Interaction with the relevant stakeholders for GBV issues was very ad-hoc in nature and the youth was not aware of the stakeholders to address the GBV issues. In the meantime, lack of linkages by the service providers with the youth groups also a reason for ignorance of GBV issues. In the meantime WRDS had some linkages with some stakeholders working on GBV (Women Development Officer (WDO), DS and other nongovernmental organizations). However the relationship was found to be not regular and very responsive mode than the proactive/prevention mode.

- Interaction with GBV related stakeholders' matrix is shown in Table 1 . The analysis of GBV stakeholder interaction with the community is shown in Figure 1. It shows that the most regular interaction to address GBV issues were GN, Police and midwife (for health issues). There was lack of 
interaction with WDO and even RDS showed lack of interest to get involved being most of the perpetrators are men in the same society.

- Only few organisations trained and conducted awareness trainings on GBV issues. No local religious institutions or civil society groups existed in the GNs of this assessment, which could play major role in addressing GBV issues.

\subsection{Future requirements of the communities to address GBV issues}

In general all study communities largely require general awareness on GBV issues, mechanisms for prevention and response. This awareness raising activities should include knowledge of gender and gender equality, understanding of gender based issues and structure mechanisms for prevention and response.

General awareness programs should further enhance the involvement of WRDS and the youth groups to stimulate in depth understanding through training programs which should help them to lead in GBV issues in their communities. There is an urgent need to establish community based GBV response mechanisms, which should not be limited to WRDS and youth, but should include RDS and other role models in the community such as religious leaders and people who have wider acceptance at the community and local authority level.

As one of the priorities, these communities should also create linkages with available mechanisms in the neighboring villages and should be able to learn and share their experience on addressing GBV issues. Linkages with the key stakeholders at the organizational level such as Legal Aid Commission should be further enhanced and regular interaction with WDO desk should be established. Interaction of WRDS with the RDS need to be further strengthened which should be able to discuss GBV related issues very openly and few members from these two societies could be brought in a sub forum to work on the GBV issues. Whereas the youth groups which have mixed of gender compositions are also ideal venues to foster the knowledge on gender based issues as they already have both sexes and already have certain level of interaction, paving the way for quicker impact of imparting the knowledge and awareness.

Table 1. Level of interaction with stakeholders of GBV for GBV related issues as perceived by participants in the focus group discussion (Number of groups agreed to the frequency of interaction, total number of study groups $n=4$ )

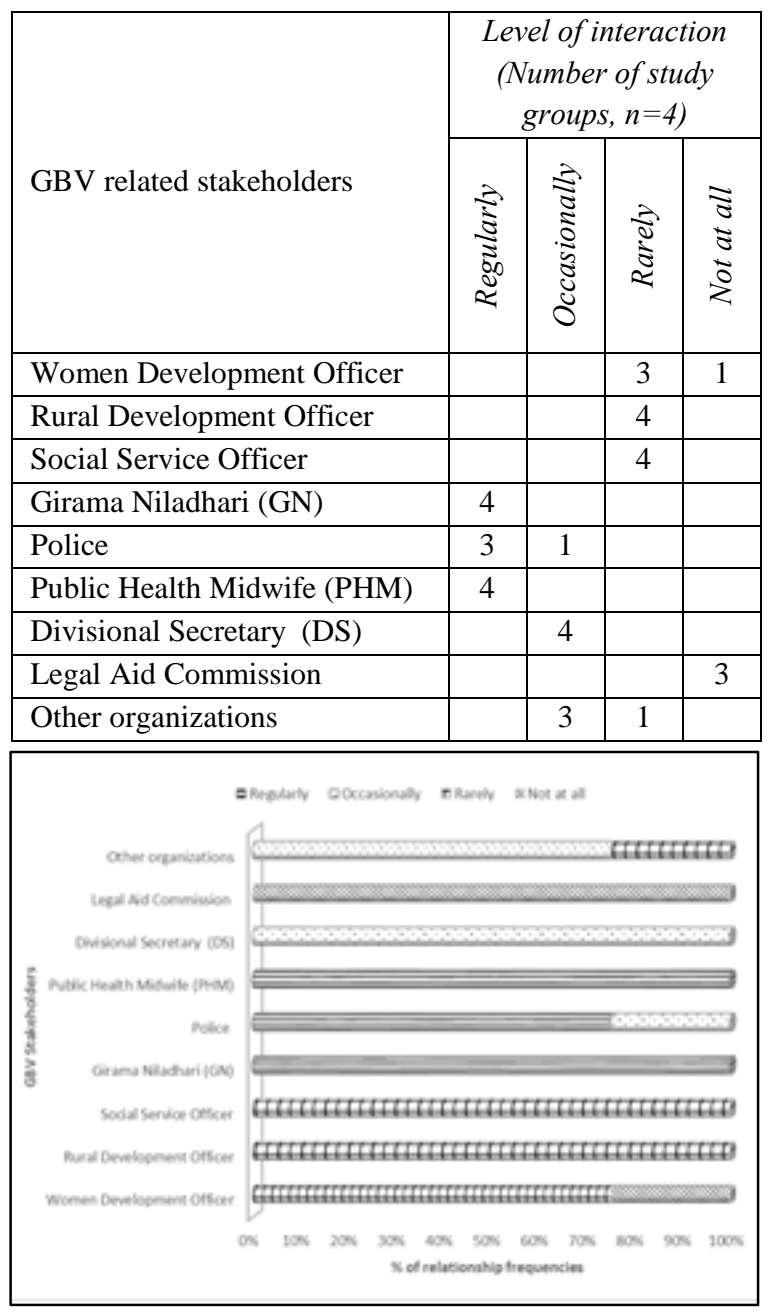

Figure 2: Level of interaction by GBV stakeholders and their interaction frequencies (Regular, Occasional, rare, and not at all) 


\section{CONCLUSION}

It can be concluded that the culturally determined traditional gender roles in the study communities limits the role of female headed households in positively contributing to the well-being of the society. Generally it is perceived that the women stay at home and it is the men who need to earn the money. Single woman has a number of practical and cultural barriers to access cash. They cannot leave young children alone at home while they go out to work and it may adversely create a bad reputation. Therefore, projects that bring a reduction in women's anxiety and an increase their confidence with the reduction in vulnerability need to be implemented. Further, a comprehensive gender analysis which could be more easily understood and respected by the local authorities in their interventions will increase the appropriateness and impact of their work with their communities.

\section{RECOMMENDATIONS}

1. Divulging positive cultural norms and values will happen over the longer period of time but the facilitation of trainings and continuous engagement of male leaders and role models in the community in women rights and referral mechanisms will help this process.

2. Women confident building programmes, particularly for the young women could be organized at community level through WRDS. This program should include information on available services, the rights of women and national customary laws on GBV in Sri Lanka.

3. The workshops could be conducted to key personnel in gender related referral mechanisms in local administration such as Girama Niladari, Women Development Officers (WDO), Divisional Secretaries, Social Service Officers and Rural Development Officers. An exercise or case study in their own working community would help to probe more into the GBV issues and will make the key interlocutors of GBV issues feel more responsible. WDOs role is very vital in the North than other areas, and their presence and interaction with the communities need to be ensured (HRC 2011).

4. A monitoring mechanism should be agreed at the Women Rural Development Society (WRDS) level and a 'community vigilant' group could be formed and trained as to how to identify GBV issues and also on prevention and response mechanisms.

5. WRDS and Youth members could be linked with the civil society groups or similar networks in neighbor villages in each district, particularly working on women issues such as Women Action Network (WAN). This will help to advocate the local authorities to attend and respond to the GBV issues. Cross learning and experience sharing to bring out the lessons learnt in GBV issues and good practices in addressing GBV issues by other communities could also be helpful.

\section{ACKNOWLEDGEMENT}

Author thanks to CARE Sri Lanka for allowing materials and reports produced as part of Safety, Security and Dignity for Women (SSDW) project in September 2013, to be reflected in this paper. The contents of this publication are the sole responsibility of the author and can in no way be taken to reflect the views of CARE Sri Lanka.

\section{REFERENCES}

CARE CARE's Commitment to Ending GenderBased Violence, CARE USA, http://www.care.org/sites/default/files/documents /GBV-2012-CARE-GBV-Program-Brief.pdf 2010. Accessed on $16^{\text {th }}$ of October 2013.

HRC STUDY on Availability of services of Women Development Officers in conflict affected areas - National Protection and Durable Solution for Internally Displaced Persons Project, Human Rights Commission of Sri Lanka. 2011. 
ICAN What the Women Say, Elusive Peace, Pervasive Violence: Sri Lankan Women's Struggle for Security and Justice, International Civil Society Action Network (ICAN) for Women's rights, peace and security, brief 8 . Spring 2013.

ICG, Sri Lanka: Women's Insecurity in the North and East, Asia Report $N^{\circ} 217$, International Crisis Group, Available in http://www.crisisgroup.org/ /media/Files/asia/so uth-asia/srilanka/217\%20Sri\%20Lanka\%20-

$\% 20$ Womens $\% 20$ Insecurity\%20in $\% 20$ the $\% 20 \mathrm{~N}$ orth\%20and\%20East\%20KO.pdf, 2011; 25-29. Accessed on 11 ${ }^{\text {th }}$ of October 2013.

JAYASUNDERE R. Understanding Gendered Violence against Women in Sri Lanka, A Background Paper for Women Defining Peace, Technical Consultant to Women Defining Peace. August 2009.

JENNIFER P, GUNAWARDANE $\mathrm{N}$ \& JAYASURIYA V. Review of Research Evidence on Gender Based Violence (GBV) in Sri Lanka, Second edition, Sri Lanka Medical Association, Colombo. 2011. 